\title{
Caracterización morfológica y análisis de crecimiento de tres cultivares de Helianthus annuus L. para flor de corte
}

\section{Morphological characterization and growth analysis of three Helianthus annuus L. varieties for cutting flower}

${ }^{1}$ Universidad Central del Ecuador. Facultad de Ciencias Agrícolas, Carrera de Agronomía. Jerónimo Leiton y Av. La Gasca s/n. Ciudadela Universitaria. Quito. 170521. Ecuador.

$\otimes$ jfcarrillo@uce.edu.ec

${ }^{2}$ Universidad Central del Ecuador. Facultad de Ciencias Agrícolas, Carrera de Agronomía. Jerónimo Leiton y Av. La Gasca s/n. Ciudadela Universitaria. Quito. 170521. Ecuador.

$\otimes$ myumbla@uce.edu.ec

D. https://orcid.org/0000-0001-5037-6581

*Autor de correspondencia:

myumbla@uce.edu.ec.

\section{SIEMBRA}

https://revistadigital.uce.edu.ec/index.php/SIEMBRA e-ISSN: $2477-8850$

\section{ISSN: $1390-8928$}

Periodicidad: semestral

vol. 9, núm. 1, 2022

siembra.fag@uce.edu.ec

DOI: https://doi.org/10.29166/siembra.v9i1.3323

Esta obra está bajo una licencia internacional Creative Commons Atribución-NoComercial

\section{Resumen}

El objetivo de este estudio fue evaluar las características morfológicas y analizar los parámetros de crecimiento de tres cultivares híbridos de girasol (Helianthus annuus L.) para flor de corte, cultivados a campo abierto. Los cultivares híbridos Vicent Choice, Sunrich Orange y SM-373 se evaluaron en un diseño de bloques completos al azar con cuatro repeticiones. El ciclo del cultivo se finalizó al $40 \%$ de apertura floral, a los 53 días después de la siembra para Vicent Choice, 55 días para Sunrich Orange y 63 para SM 373. La longitud del tallo promedio para los tres cultivares fue $87,36 \mathrm{~cm}$. La dinámica de crecimiento de los tres cultivares se ajustó a un modelo cuadrático, en el que el tallo presentó el 50,12\% del total de materia seca promedio, y el cultivar híbrido Vicent Choice obtuvo la mayor acumulación de masa seca total $(42,54 \mathrm{~g})$. La floración fue el estado de desarrollo con mayor eficiencia fotosintética y el índice de área foliar promedio de los tres cultivares fue de 1,33 a los 46 días después de la siembra, y Vicent Choice produjo 679 tallos exportables, lo que representó el $70,72 \%$ del total de la producción del estudio.

Palabras clave: girasol, floricultura, flores de verano, análisis de crecimiento, parámetros de crecimiento.

\begin{abstract}
The aim of this study was to evaluate the flower morphological characteristics and analyze the growth parameters for cut-flower of three sunflower hybrid cultivars (Helianthus annuus L.), coming from open field cultivation. Hybrid cultivars Vicent Choice, Sunrich Orange and SM-373 were evaluated in a Complete Block Design with four replicates. The cycle of sunflower cultivation was finalized at $40 \%$ flower opening, which occurred at 53 days after planting for Vicent Choice, 55 days for Sunrich Orange and 63 days for SM-373. In this study, the three hybrid cultivars stem length average was $87.36 \mathrm{~cm}$. The growth dynamic of the three varieties was adjusted to a quadratic model, in which the stem yielded in average $50.12 \%$ of dry matter, and the Vicent Choice hybrid cultivar recorded the highest total dry matter accumulation $(42.54 \mathrm{~g})$. Flowering was the development stage with highest photosynthetic efficacy,
\end{abstract}


the average foliar area index of the three varieties was 1.33 at 46 days after planting, and Vicent Choice produced 679 exportable stems, representing $70.72 \%$ of the study's total production.

Keywords: sunflower, floriculture, summer flowers, growth analysis, growth parameters.

\section{Introducción}

El girasol (Helianthus annuus L.) es una planta anual originaria de América del Norte, resistente a la sequía, de ciclo corto y con baja exigencia nutricional. Es un cultivo que se adapta bien a diferentes condiciones edáficas y climáticas, se desarrolla mejor en suelos profundos, ligeramente alcalinos y con buen drenaje (Gómez-Arnau, 2004).

El girasol, como flor de corte, en el mundo de la ornamentación, es valioso por su alta demanda para la floristería (Trápani, 2004). Según Expoflores (2020) en Ecuador existen aproximadamente 4.900 ha cultivadas con flores, entre ellas: rosas, liatris, cartuchos, gypsophila, hypericum, girasoles, claveles; de éstas, el girasol ocupa aproximadamente 110 ha, las mismas que están distribuidas principalmente en la provincia de Pichincha, seguido por Imbabura, Azuay y Cotopaxi. La producción en promedio de tallos de girasol de corte de una hectárea, dependiendo del tamaño de la inflorescencia y la densidad de siembra, está entre 300.000 y 450.000 ; el $10 \%$ para el mercado nacional y el $90 \%$ para la exportación.

El cultivo de girasol es de fácil adaptación y de menores requerimientos nutricionales e hídricos, permite una salida rentable para los productores locales y la demanda de exportación de esta especie en las empresas florícolas (Tenesaca, 2015). Las principales cultivares de girasol como flor de corte sembrabas en Ecuador son híbridos provenientes de Sakata seeds, entre ellos se destacan cultivares resultantes de líneas como sunbright, sunrich, vicents, carmel, entre otras (Sakata, 2021).

La caracterización morfológica de una especie vegetal es la descripción de un grupo de caracteres cuantitativos y cualitativos sobre el comportamiento, forma y estructura de ciertas cultivares, determinados por su genética, forman parte de las características internas de una especie y pueden ser modificadas por el manejo del cultivo, como densidad de siembra, fertilizantes, etc. (Ortiz et al., 2017). Según Barrera et al. (2010) el análisis de crecimiento permite el estudio del periodo vegetativo, basado en una aproximación de caracteres cuantitativos, que usa datos básicos para la interpretación de las especies vegetales que crecen en un ambiente controlado. La intención principal de esta técnica es dar información biométrica y estudios fisiológicos de las especies, para que los investigadores la incluyan en sus programas de mejora genética, el adecuado manejo agronómico y la reducción de técnicas culturales innecesarias (Gabriel et al., 2016).

Mundialmente existen estudios de las características morfológicas y el análisis de crecimiento del girasol para la producción de aceite, estudios que elevan la productividad del cultivo (dos-Santos et al., 2017). En Ecuador existen pocos estudios centrados en el análisis de crecimiento de las cultivares de girasol para flor de corte cultivadas, cuya producción generalmente se maneja de forma tradicional, siendo importante realizar investigaciones para el manejo del cultivo y sus respectivas prácticas agronómicas, que influyen en los costos de producción y en la calidad de la flor para el mercado (Penichet Cortiza, 2008); por ello, el objetivo de la presente investigación fue evaluar la caracterización morfológica y efectuar el análisis de crecimiento de tres cultivares de girasol para flor de corte.

\section{Materiales y Métodos}

La presente investigación se realizó bajo un diseño de bloques completos al azar (DBCA) con tres tratamientos: cultivares de girasol Vicent choice (VC), Sunrich orange (SO) y Código SM 373 (CSM), y cuatro bloques para cada tratamiento.

Para tener uniformidad en el suelo y lograr la germinación de la semilla, inicialmente se hizo un pase de arado de disco y rastra. Se levantaron las camas, de $1 \mathrm{~m}$ de ancho por $30 \mathrm{~m}$ de largo, junto con fertilizante de fondo (48-50-60 con una dosis de $10 \mathrm{~g} \mathrm{~m}^{-2}$ ). Enseguida se realizaron los huecos con un marcador metálico a una distancia de $16 \mathrm{~cm}$ entre plantas y $20 \mathrm{~cm}$ entre hileras; la siembra se realizó el 3 de mayo del 2019, se colocó una semilla por golpe con una densidad de siembra de 30 plantas por $\mathrm{m}^{2}$. Para evitar que las plantas se quiebren, se empleó una malla de tutoreo. 
Después de 15 días de la emergencia de las plántulas, se abonó con fertilizante sólido (48-50-60 con dosis de $\left.10 \mathrm{~g} \mathrm{~m}^{-2}\right)$; la fertilización foliar se realizó a los 35 días con fertilizante (20-20-20 con dosis de $\left.2 \mathrm{~g} \mathrm{l}^{-1}\right)$ y a los 50 días con micronutrientes (EDTA de magnesio, azufre, hierro, manganeso y zinc con dosis de $2 \mathrm{ml} / \mathrm{l}$ ). El sistema de riego fue por goteo, se activó dos veces al día, para el fertirriego los fertilizantes fueron distribuidos por medio del venturi en toda la parcela (urea con dosis de $20 \mathrm{~g} \mathrm{~m}^{-2}$, nitrato de amonio, nitrato de calcio, nitrato de magnesio, sulfato de potasio y fosfato mono amónico, todos con dosis de $10 \mathrm{~g} \mathrm{~m}^{-2}$ ) y se activaba los días martes y viernes con una duración de cinco minutos durante todo el ciclo del cultivo.

El control de las malezas fue realizado manualmente a los 27 días después de la siembra (DDS). Para el control de plagas y enfermedades se realizó un cronograma siguiendo las recomendaciones de productos y dosificaciones con base en el protocolo de la empresa.

La cosecha se realizó cuando los botones florales tuvieron $10 \%$ de apertura, con un corte a $10 \mathrm{~cm}$ del cuello del tallo y se colocó en cámaras de refrigeración.

Las evaluaciones realizadas durante el experimento se tomaron en cada una de las unidades experimentales ( $1 \mathrm{~m}$ de ancho por $10 \mathrm{~m}$ de largo), inicialmente se tomó el porcentaje de emergencias (PE), evaluando todas las plantas netas del experimento, desde la siembra hasta los 15 días posteriores, registrando los datos cada tres días, expresados en unidades (plántulas emergidas) en el tiempo (días) y en porcentaje (\%), utilizando la ecuación [1].

$$
\% \text { Emergencia }=\left(\frac{S T-S N E}{S T}\right) \times 100
$$

donde,

- $\quad S T$ : semillas totales.

- $\quad S N E$ : semillas no emergidas.

Los días a la emergencia (DE) fueron evaluados cuando las cultivares de girasol utilizadas presentaron un porcentaje de emergencia constante en el tiempo, la variable se expresó en días. Durante el ciclo de cultivo se realizaron evaluaciones con dos tipos de muestreo:

a. Muestreo no destructivo: de acuerdo con la metodología de Montoya et al. (2007) por cada unidad experimental se marcaron 10 plantas de cada cultivar, y se evaluaron cada diez días las siguientes variables: a.1. Caracterización morfológica:

- Forma de las hojas (FH), obovada, cordada o acorazonada, mediante una descripción visual, tomando tres hojas por planta.

- Longitud del tallo (LT), se midió con cinta métrica expresada en cm, desde el inicio del cuello del tallo hasta la base del pedúnculo floral.

- Diámetro del tallo (DT), se midió con un calibrador digital y se expresa en mm, tomando en cuenta como punto de medición $10 \mathrm{~cm}$ sobre la base del cuello del tallo y la mitad de la longitud del tallo.

- Número de hojas $(\mathrm{NH})$, se contabilizaron solo las hojas verdaderas expresadas en unidades.

- Número de entrenudos (NE), expresados en unidades.

- Diámetro de inflorescencia (DI) desde la aparición del botón floral hasta el punto de corte, lo que se midió con un calibrador digital expresado en $\mathrm{mm}$.

a.2. Identificación de los estadios fenológicos

- Se realizaron observaciones morfológicas de las plantas cada diez días a partir de los 16 DDS, correspondiente a la fase de desarrollo de las hojas (tallo principal) hasta la cosecha. Con base en esas observaciones se identificaron las fases fenológicas tomando como referencia la escala desarrollada por Biologische Bundesanstait Bundessortenamt and Chemical Industry (BBCH, 1998).

b. Muestreo destructivo para el análisis de crecimiento: cada unidad experimental estaba constituida por tres plantas/muestreo. Cada diez días se colectaron las muestras, con un total de seis muestreos durante el periodo que se efectuó la investigación, colectando material vegetal para el análisis en laboratorio. De acuerdo con la metodología de Borrego et al. (2000) se evaluaron cinco parámetros esenciales basados en tres variables: masa fresca, masa seca y área foliar para conocer la dinámica de crecimiento de cada uno de los tratamientos. 
- $\quad$ Masa fresca (MF), se pesó el tallo, hojas e inflorescencia con una balanza analítica expresada en g.

- $\quad$ Masa seca (MS), según la metodología de Di Benedetto y Tognetti (2016), las muestras tomadas de tallo, hojas e inflorescencia se secaron en una estufa a $65^{\circ} \mathrm{C}$ durante 72 horas, se pesó la MS con una balanza analítica expresada en $\mathrm{g}$.

- $\quad$ Área foliar (AF), según la metodología de Rincón Guerrero et al. (2012) las muestras foliares de las plantas fueron extirpadas y colocadas en un fondo blanco 5PB 5/8 según la tabla de Munsell, junto con una línea de referencia de $2 \mathrm{~cm}$, se las fotografió mediante una cámara digital semiprofesional y se procesó la imagen en el software ImageJ, expresado en $\mathrm{cm} 2$.

- Longitud de raíz (LR), se midió con cinta métrica expresada en cm.

- $\quad$ Peso de raíz (VR), se pesó con una balanza analítica expresado en g.

Con base en la MS, MF y AF se calcularon los parámetros para los análisis de crecimiento (Tabla 1).

Tabla 1. Parámetros de crecimiento establecidos.

Table 1. Established growth parameters.

\begin{tabular}{|c|c|c|c|}
\hline Parámetro & Símbolo & Unidad & Ecuación* \\
\hline Tasa de crecimiento absoluto & TCA & $\mathrm{g} \mathrm{día}^{-1}$ & $T C A=\frac{W_{2}-W_{1}}{T_{2}-T_{1}}$ \\
\hline Tasa de crecimiento relativo & TCR & $\mathrm{g} \mathrm{g}^{-1} \mathrm{dí}^{-1}$ & $T C R=\frac{L n W_{2}-L n W_{1}}{T_{2}-T_{1}}$ \\
\hline Tasa de crecimiento del cultivo & TCC & $\mathrm{g} \mathrm{cm}^{-2}$ día $^{-1}$ & $T C C=\frac{\frac{1}{A S} x\left(W_{2}-W_{1}\right)}{T_{2}-T_{1}}$ \\
\hline Índice de área foliar & IAF & $\begin{array}{l}\text { Dimensional según } \\
\text { las unidades }\end{array}$ & $I A F=\frac{A F_{2}-A F_{1}}{A S}$ \\
\hline Relación área foliar & RAF & $\mathrm{cm}^{2} \mathrm{~g}^{-1}$ & $R A F=\frac{\frac{A F_{2}}{W_{2}}+\frac{A F_{1}}{W_{1}}}{T_{2}-T_{1}}$ \\
\hline
\end{tabular}

* $A F$ : área foliar; $A S$ : área sembrada; $W$ : masa seca; $T$ : tiempo; $L n$ : logaritmo natural

Al final del ciclo también fueron evaluados los días para la cosecha (DC), contabilizando el tiempo de cultivo de las plantas marcadas, desde la siembra hasta la cosecha, expresado en días. Así también, fue evaluada la producción (PR) mediante la determinación del número de tallos de girasol, en las diferentes categorías comerciales (Tabla 2).

Tabla 2. Criterios para clasificación comercial de los tallos de girasol. Table 2. Criteria for commercial grading of sunflower stems.

\begin{tabular}{llll}
\hline Grados & Tamaño del capítulo & Grosor del tallo & Largo del tallo \\
\hline Selecto & $>8,1 \mathrm{~cm}$ & $>2,0 \mathrm{~cm}$ & $80-90 \mathrm{~cm}$ \\
Médium & $6,1-8,0 \mathrm{~cm}$ & $1,1-1,9 \mathrm{~cm}$ & $70-79 \mathrm{~cm}$ \\
Pequeño & $4,5-6,0 \mathrm{~cm}$ & $0,5-1,0 \mathrm{~cm}$ & $60-69 \mathrm{~cm}$ \\
\hline
\end{tabular}

El ADEVA determinó la diferencia estadística de las variables en estudio con los valores T, p-valor y cpMalloows. Se evaluaron la influencia de las variables independientes (tres cultivares de girasol) sobre las dependientes, las características morfológicas y los parámetros de crecimiento.

La comparación de medias de las variables en estudio se realizó mediante una prueba de Tukey al $5 \%$ con previa comprobación de los supuestos de normalidad y homogeneidad de varianza, utilizando el paquete estadístico InfoStat versión 1.0 (Di Rienzo et al., 2012). Se realizó un análisis de regresión de las variables presentes en la investigación con respecto al tiempo de su evaluación. 


\section{Resultados y Discusión}

\subsection{Emergencia y ciclo del cultivo}

Los promedios de porcentaje de emergencia, días a la emergencia y días a la cosecha de los tratamientos en estudio presentan diferencias estadísticamente significativas mediante el ADEVA (Anexo 1). Para las tres evaluaciones fueron observadas diferencias de significancia, siendo la cultivar CSM la que presenta menor porcentaje de emergencia, mayor número de días para la emergencia y mayor tiempo para llegar al punto de cosecha en relación con las otras cultivares (Tabla 3 ).

Tabla 3. Comparación de medias* para porcentaje de emergencia, días a la emergencia y días a la cosecha de tres cultivares híbridos de girasol. Table 3. Mean comparison of emergence percentage, days to emergence and days to harvest of three hybrid sunflower cultivars.

\begin{tabular}{llll}
\hline Identificación & Porcentaje de germinación & Días a la germinación & Días a la cosecha \\
\hline $\mathrm{SO}$ & $98,85 \mathrm{~A}$ & $12,75 \mathrm{~A}$ & $53 \mathrm{~A}$ \\
$\mathrm{VC}$ & $97,85 \mathrm{~A}$ & $10,50 \mathrm{~A}$ & $55 \mathrm{~A}$ \\
$\mathrm{CSM}$ & $93,82 \mathrm{~B}$ & $15,00 \mathrm{~B}$ & $63 \mathrm{~B}$ \\
\hline $\mathrm{CV}(\%)$ & 0,88 & 8,77 & 15,23 \\
\hline
\end{tabular}

* Medias con una letra común verticalmente no son significativamente diferentes por la prueba Tukey (p-valor $>0,05)$.

Los tres tratamientos alcanzaron altos porcentajes de germinación, mayor al $90 \%$ a los 9 DDS (Figura 1) los valores obtenidos en el estudio son similares a los porcentajes de germinación descritos por los obtentores Sakata (2021), quienes indican que el porcentaje de germinación de las cultivares VC, SO y CSM son del $99,50 \%, 98,80 \%$ y $95 \%$, respectivamente.

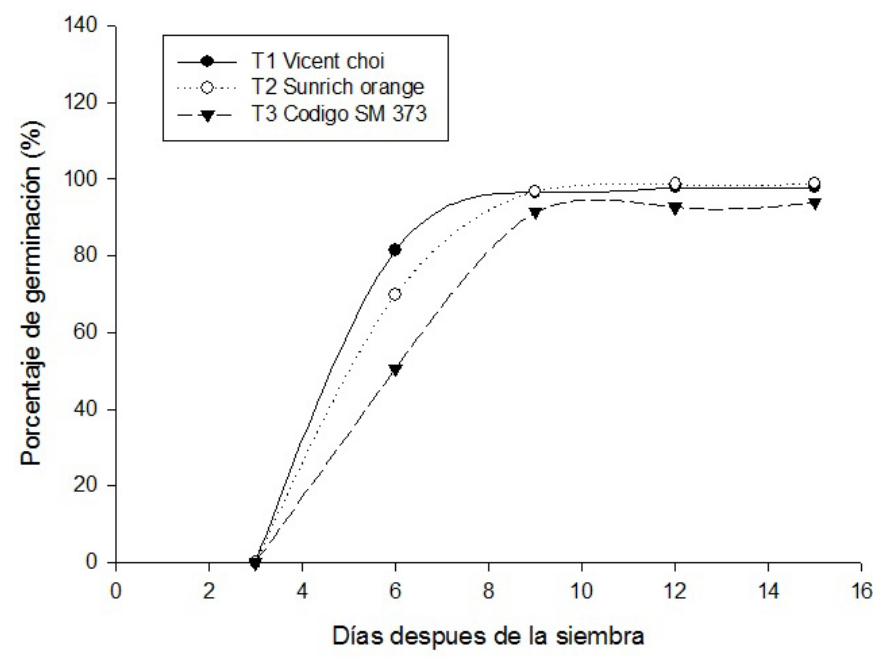

Figura 1. Dinámica del porcentaje de germinación durante 15 días posteriores a la siembra en los cultivares híbridos Vicent Choice, Sunrich Orange y SM-373.

Figure 1. Dynamics of germination percentage during the 15 days after sowing in the hybrid cultivars Vicent Choice, Sunrich Orange and SM-373.

La cultivar CSM necesitó mayor cantidad de días para la cosecha, de esta forma se logra categorizar a esta cultivar en un grupo de girasoles de precoz-tardía; por otro lado, la línea parental Sunrich son cultivares comerciales precoces, con 55 días para florecer obtentores (Sakata, 2021).

\subsection{Caracterización morfológica}

El girasol es una especie dicotiledónea con un ciclo de vida corto en comparación a otras flores de corte destinadas a la floristería (Olalde Gutiérrez et al., 2000), las tres cultivares de girasol presentaron cinco fases de desarrollo principales (Tabla 4), consecuentes a fases secundarias dentro de ellos marcados por un código (Lancashire et al., 1991; Weber y Bleiholder, 1990). 
Tabla 4. Escala BBCH para fases de desarrollo del girasol.

Table 4. BBCH scale for sunflower developmental phases.

\begin{tabular}{|c|c|c|c|c|}
\hline \multicolumn{3}{|c|}{ Cultivares en estudio* } & \multicolumn{2}{|r|}{ Escala BBCH } \\
\hline \multicolumn{3}{|c|}{ DDS } & \multirow{2}{*}{ Código } & \multirow{2}{*}{ Descripción } \\
\hline VC & SO & CSM & & \\
\hline & & & \multicolumn{2}{|c|}{ Estadio principal 1: Desarrollo de las hojas (tallo principal) } \\
\hline & & & 10 & Cotiledones totalmente desplegados \\
\hline & & 16 & 12 & Primer par de hojas desplegadas \\
\hline \multirow[t]{2}{*}{16} & 16 & & 14 & Segundo par de hojas desplegadas \\
\hline & & 26 & 15 & 5 hojas desplegadas \\
\hline 26 & 26 & 36 & 17 & 7 hojas desplegadas \\
\hline $36 / 46$ & $36 / 46$ & 46 & 19 & 9 o más hojas desplegadas \\
\hline & & & \multicolumn{2}{|c|}{ Estadio principal 3: Crecimiento longitudinal del tallo principal } \\
\hline & & & 30 & Comienzo del crecimiento longitudinal del tallo \\
\hline & & & 31 & 1 entrenudo, alargado visiblemente \\
\hline & & 26 & 32 & 2 entrenudos, alargados visiblemente \\
\hline 26 & 26 & 36 & 34 & 3-4 entrenudos, alargados visiblemente \\
\hline 36 & 36 & 46 & 37 & 5-8 entrenudos, alargados visiblemente \\
\hline 46 & 46 & & 39 & 9 o más entrenudos, alargados visiblemente \\
\hline \multicolumn{5}{|c|}{ Estadio principal 4: Aparición del órgano floral (tallo principal) } \\
\hline \multirow{5}{*}{46} & & 46 & 51 & Inflorescencia (capítulo) recién visible entre las hojas más jóvenes \\
\hline & & & 53 & $\begin{array}{l}\text { Inflorescencia (capítulo) se comienza a separar de las hojas más jóvenes; las brác- } \\
\text { teas se pueden distinguir de las hojas del follaje }\end{array}$ \\
\hline & 46 & & 55 & Inflorescencia (capítulo) separada de las hojas más jóvenes del follaje \\
\hline & & & 57 & Inflorescencia (capítulo) completamente separada de las hojas del follaje \\
\hline & & & 58 & Flores de la corona visibles entre las brácteas; inflorescencia (capítulo) aún cerrada \\
\hline \multicolumn{5}{|c|}{ Estadio principal 6: Floración (tallo principal) } \\
\hline \multirow{4}{*}{66} & & 66 & 61 & $\begin{array}{l}\text { Comienzo de la floración: las flores de la corona se alargan; las flores tubulosas del } \\
\text { disco son visibles en el tercio exterior de la inflorescencia (capítulo) }\end{array}$ \\
\hline & & & 63 & $\begin{array}{l}\text { Las flores tubulosas del disco del tercio exterior de la inflorescencia (capítulo), en } \\
\text { floración (estambres y estigmas, visibles) }\end{array}$ \\
\hline & & & 65 & $\begin{array}{l}\text { Plena floración: las flores tubulosas del disco del tercio medio de la inflorescencia } \\
\text { (capítulo), en floración (estambres y estigmas, visibles) }\end{array}$ \\
\hline & 66 & & 67 & $\begin{array}{l}\text { La floración decae: las flores tubulosas del disco del tercio interior de la inflores- } \\
\text { cencia (capítulo), en floración (estambres y estigmas, visibles) }\end{array}$ \\
\hline
\end{tabular}

* DDS: días después de la siembra; VC: Vicent choice; SO: Sunrich orange; CSM: Código SM 373.

En la Figura 2 puede observarse en fotografías las fases de desarrollo de las tres cultivares de girasol según la época de colecta $(16,26,36,46,56$ y 66 DDS) que se realizó durante la investigación. A los 16 DDS las tres cultivares presentaron hojas cordadas, VC y SO se encajaron en el código 14, mientras que la cultivar CSM en el código 12, las tres cultivares presentaron color morado del tallo. Corral et al. (2014) mencionan que los tallos de girasol poseen antocianinas, las cuales reaccionan con $\mathrm{pH}$ del suelo, los tallos al mostrar tonalidades moradas indican que el $\mathrm{pH}$ del suelo es neutro.

A los 26 DDS las cultivares VC y SO presentaron siete y seis hojas cordadas, respectivamente, así como tres entrenudos prominentes (código 17 y 34), mientras que la cultivar CSM presentó cinco hojas cordadas con dos entrenudos (código 15 y 32, respectivamente), en las tres cultivares el color del tallo es verde con pubescencias blancas, los tallos se tornan verdes porque en esta fase de desarrollo ya existe presencia de clorofila en el tallo (Corral et al., 2014).

A los 36 DDS las tres cultivares presentaron mayor número de hojas cordadas, las cultivares VC y SO se ubicaron en los códigos 19 y 37, mientras que la cultivar CSM presentó solo ocho hojas (código 17) y cuatro entrenudos (código 34). En las cultivares VC y SO, existe un mayor número de entrenudos, lo cual está relacionado con el número de nudos que dan origen a las hojas, que incide en mayor cantidad de área foliar y masa seca siendo estas cultivares más productivas en comparación con CSM. 

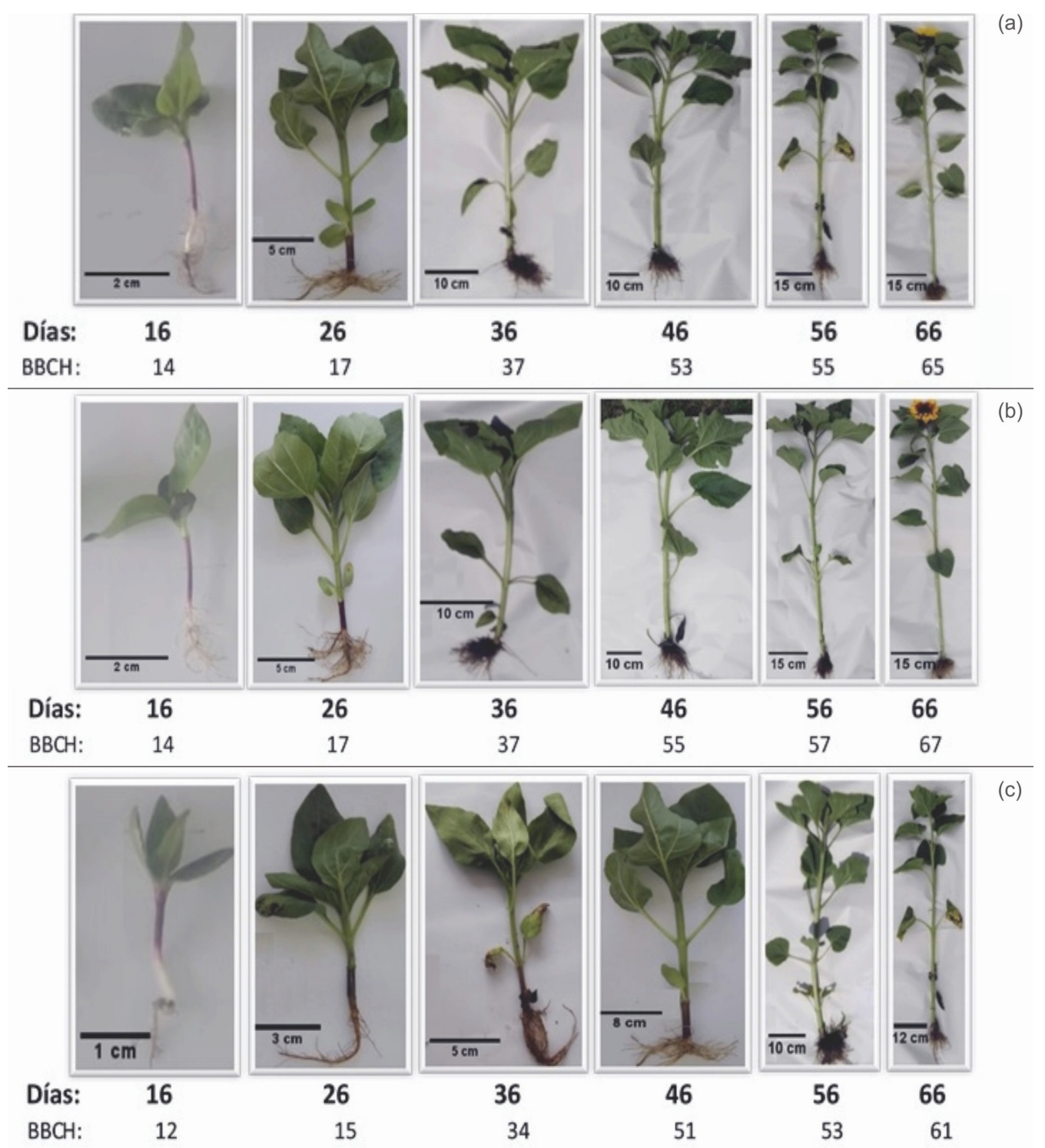

Figura 2. Fases de desarrollo de girasol (Helianthus annus L.) para los cultivares híbridos Vicent Choice (a), Sunrich Orange (b) y SM-373 (c). Figure 2. Developmental stages of sunflower (Helianthus annus L.) for hybrid cultivars Vicent Choice (a), Sunrich Orange (b) and SM-373 (c).

A los 46 DDS las tres cultivares se ubicaron en el código 19, adicionalmente las cultivares VC y SO presentaron nueve entrenudos marcados (código 39), mientras que la cultivar CSM presentó solo seis entrenudos (código 37). En este punto todas las cultivares presentaron desarrollo de la inflorescencia, en la cultivar VC la inflorescencia comenzaba a separarse de las hojas más jóvenes con brácteas notorias (código 53) con un diámetro promedio de $22 \mathrm{~mm}$, la cultivar SO presentó una inflorescencia completamente separada de las hojas más jóvenes (código 55) con un diámetro promedio de $24 \mathrm{~mm}$ y la cultivar CSM presentó una inflorescencia apenas visible entre las hojas más jóvenes (código 51) con un diámetro promedio de $16 \mathrm{~mm}$. Cuando inicia el proceso de floración, se producen cambios fisiológicos en la planta, específicamente en los meristemos, los cuales se diferencian en meristemos florales, esto provoca que la planta no desarrolle su crecimiento vegetativo; todas las reservas nutricionales sirven para que se forme las nuevas inflorescencias (Olalde Gutiérrez et al., 2000).

A los 56 DDS las tres cultivares detuvieron su crecimiento vegetativo. Escalante Estrada (1999) menciona que esto se debe a que las hojas bajeras son las primeras en presentar senescencia, dejando de ser fotosintéticamente activas, además los fotoasimilados son destinados hacia los órganos reproductivos, en este punto la planta de girasol genera pocos brotes que dan origen a nuevas hojas. Las cultivares VC y SO presentaron diez entrenudos marcados (código 39) mientras que la cultivar CSM presentó solo siete entrenudos (código 37). En este punto la cultivar VC presentó una inflorescencia separada de las hojas más jóvenes con brácteas notorias (código 55) con un diámetro promedio de $39 \mathrm{~mm}$, la cultivar SO presentó una inflorescencia completamente separada de las hojas más jóvenes con flores de la corona visibles entre las brácteas (código 57) y un diámetro 
promedio de $40 \mathrm{~mm}$, y la cultivar CSM presentó una inflorescencia que comienza a separarse de las hojas más jóvenes (código 53) con un diámetro promedio de $26 \mathrm{~mm}$. Las medidas de las cultivares VC y SO, están en el rango del diámetro promedio descrito por Escalante Estrada et al.(2015) según el cual la inflorescencia de $H$. annuus tiene un promedio de $35 \mathrm{~mm}$ de diámetro a los 50 DDS.

En la fase principal de floración a los 66 DDS, las tres cultivares finalizaron el aumento de entrenudos en el tallo, además las hojas del estrato superior llegaron a su madurez. La cultivar VC en su etapa de floración, presentó flores tubulosas del disco en el tercio medio de la inflorescencia (código 65) con un diámetro promedio de $78 \mathrm{~mm}$, la cultivar SO presentó flores tubulosas del disco en el tercio interior de la inflorescencia (código 67) con un diámetro promedio de $80 \mathrm{~mm}$ y la cultivar CSM mostró una inflorescencia en la cual las flores de la corona eran alargadas mientras que las flores del disco eran visibles en el tercio medio de la misma (código 61) con un diámetro promedio de $40 \mathrm{~mm}$.

\subsection{Masa fresca y seca}

Los promedios de masa fresca y masa seca de la parte aérea del girasol en el punto de corte de los tratamientos en estudio presentan diferencias significativas mediante el ADEVA (Anexo 2). Para las dos evaluaciones fueron identificados tres rangos de significancia, la cultivar VC tuvo mayor acumulación de masa fresca y masa seca en relación con las otras cultivares (Tabla 5).

Tabla 5. Comparación de medias* para masa fresca y masa seca de la parte aérea para tres cultivares híbridos de girasol. Table 5. Mean comparison of foliar fresh and dry matter of three sunflower hybrid cultivars.

\begin{tabular}{lcc}
\hline Identificación & Masa fresca & Masa seca \\
\hline VC & $317,32 \mathrm{~A}$ & $34,79 \mathrm{~A}$ \\
SO & $189,58 \mathrm{~B}$ & $23,71 \mathrm{~B}$ \\
$\mathrm{CSM}$ & $124,37 \mathrm{C}$ & $16,48 \mathrm{C}$ \\
\hline $\mathrm{CV}(\%)$ & 15,28 & 11,71 \\
\hline * Medias con una letra común verticalmente no son significativamente diferentes por la prueba Tukey (p-valor $>0,05)$.
\end{tabular}

El promedio de masa fresca y seca de las tres cultivares fue de 210,14 y 24,99 g respectivamente, sin embargo, la cultivar VC obtuvo valores de masa fresca y seca por encima de la media general, debido a que esta cultivar presentó mayor número de hojas y entrenudos con respecto a las otras cultivares; por el contrario, la cultivar CSM presentó escaso número de hojas y entrenudos, generando menor materia vegetal. Pereira Crespo et al. (2014) destacan que, en cultivares de girasol para forraje, obtuvieron un promedio de 34,10 g de materia seca de la parte aérea (hojas, tallos e inflorescencia) a los 50 DDS. De esta forma se puede establecer la masa fresca como un parámetro de medición en posteriores investigaciones sobre girasol en cultivares precoces.

\subsection{Crecimiento}

El diámetro y longitud del tallo de las tres cultivares de girasol se ajustaron a un modelo lineal con un $\mathrm{R}^{2}$ promedio de 0,94 (Figura 3).

El diámetro y la longitud del tallo son parámetros importantes en la evaluación del cultivo de girasol. Según dos-Santos et al. (2017) la longitud del tallo está directamente relacionada con la capacidad fotosintética de la planta, a mayor producción de fotoasimilados mayor es la ganancia de medida de estas variables, es así que en nuestra investigación $\mathrm{VC}$ es la cultivar más eficiente, con mayor diámetro $(16,60 \mathrm{~mm})$ y longitud $(120,21$ $\mathrm{cm}$ ) del tallo a los 66 DDS en comparación con otras cultivares. En un estudio realizado por dos-Santos et al. (2017) en función del agua nitrogenada en girasol, afirman que el diámetro y la longitud del tallo mantienen su crecimiento hasta los 60 DDS, debido al proceso fisiológico de acumulación de materia seca, principalmente en este órgano de la planta, que actúa como reservorio de alimento para la formación de órganos futuros.

\subsection{Dinámica del crecimiento}

El peso de las cultivares de girasol y sus respectivos órganos se ajustaron a un modelo cuadrático con un $\mathrm{R}^{2}$ promedio de 0,86 (Figura 4). 


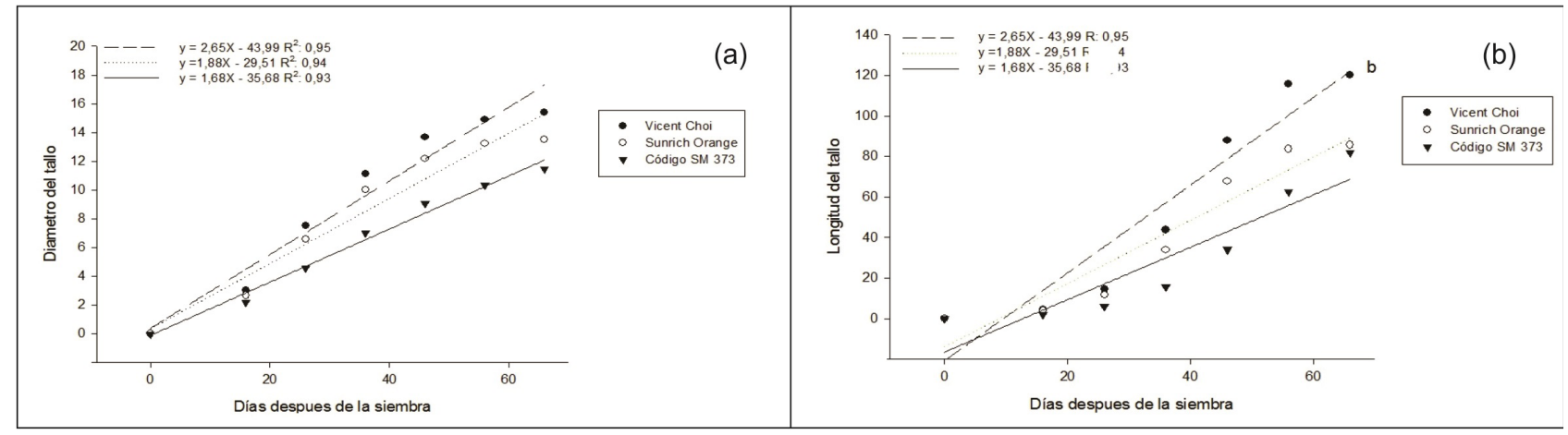

Figura 3. Diámetro (a) y longitud (b) de tallo de tres cultivares híbridos de girasol en función del ciclo del cultivo.

Figure 3. Stem diameter (a) and stem length (b) of three sunflower hybrid cultivars during the crop cycle.
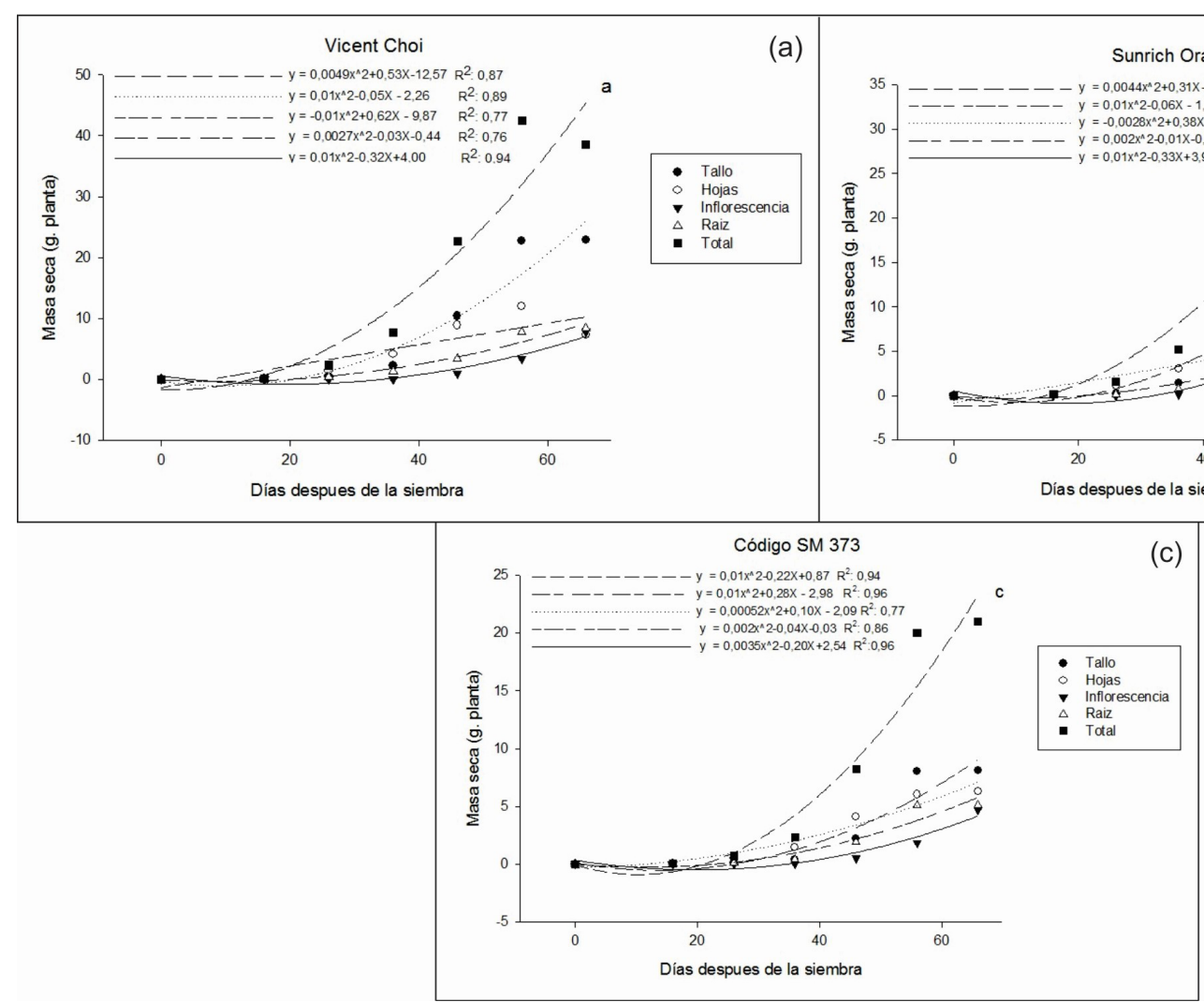

(b)

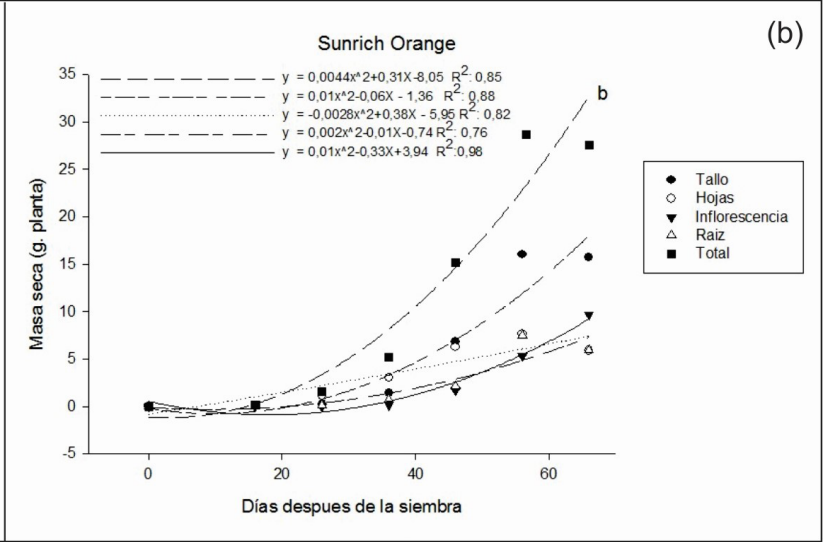

(c)

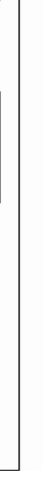

Figura 4. Dinámica de acumulación de la materia seca por órgano de la planta para los cultivares híbridos Vicent Choice (a), Sunrich Orange (b) y SM-373 (c).

Figure 4. Dynamics of dry matter accumulation for plant parts of the hybrid cultivars Vicent Choice (a), Sunrich Orange (b) and SM-373 (c).

La tendencia observada en este estudio se caracterizó por seguir una curva biológica para el crecimiento de especies vegetales. Barrera et al. (2010) mencionan que los cultivos de ciclo corto generalmente presentan esta forma de acumulación de masa seca durante su ciclo biológico debido a que existe un rango de días que las plantas necesitan de mayor producción y acumulación de materia seca para la formación de nuevos órganos, principalmente para la floración, y en el caso de tubérculos para la tuberización, pasada esta fase de desarrollo las plantas comienzan a perder masa seca por la senescencia de la misma, en este estudio esta fase no fue observada ya que el ciclo del girasol de corte finaliza con la flor cerrada y no se observa la senescencia.

Para las tres cultivares estudiadas se observó que el órgano con mayor acumulación de MS durante el ciclo de cultivo de girasol es el tallo (16,38 g), seguido por las hojas $(8,66 \mathrm{~g})$, la inflorescencia $(7,40$ g) y la raíz $(6,98 \mathrm{~g})$. Los primeros 56 días del cultivo se acumuló la mayor MS; así la cultivar VC acumuló mayor masa seca $(42,54 \mathrm{~g})$ en comparación con las otras cultivares, constituyendo la MS de tallo un $54,59 \%$ del peso total de la planta. Un estudio realizado en girasol para forraje por Pereira Crespo et al., 
(2014) afirma que los tallos de girasol son los órganos con mayor ganancia de MST en todo el ciclo del cultivo, debido a que este órgano actúa como almacén de reservas, utilizadas en momentos específicos del desarrollo como el surgimiento de un nuevo órgano.

El surgimiento de la inflorescencia fue observado entre los 36 y 46 DDS para todas las cultivares, el crecimiento de este órgano se caracterizó por ser lento hasta la cosecha con una ganancia de peso promedio de $0,039 \mathrm{~g} \mathrm{día}^{-1}$, y rápida a partir de los 56 DDS en el estado de plena floración con una ganancia de peso promedio de $0,485 \mathrm{~g}$ día $^{-1}$, este proceso fisiológico del girasol demuestra cómo un órgano específico de la planta actúa como sumidero de alimento, pasando a ser el nuevo vertedero de desarrollo de la planta.

\subsection{Tasas de crecimiento}

\subsubsection{Tasa de crecimiento absoluto}

La tasa de crecimiento absoluto (TCA) fue mayor en la cultivar VC, con valor máximo $\left(1,99 \mathrm{~g}\right.$ día $\left.{ }^{-1}\right)$ a los 56 DDS en comparación con las otras cultivares, específicamente esta cultivar tuvo mayor necesidad de agua y alimento para sus procesos fisiológicos de crecimiento. La TCA es la primera derivada o la pendiente de la curva de acumulación de masa seca (Di Benedetto y Tognetti, 2016), esta permite estimar la cantidad de agua y fotoasimilados que requiere la parte aérea de la planta (Mora-Aguilar et al., 2006). En las tres cultivares de girasol la TCA tuvo mayor acumulación de $\mathrm{g} \mathrm{día}^{-1} \mathrm{en} \mathrm{la} \mathrm{fase} \mathrm{de} \mathrm{crecimiento} \mathrm{longitudinal} \mathrm{del} \mathrm{tallo} \mathrm{hasta} \mathrm{el} \mathrm{fi-}$ nal de la floración (Figura 5). Luego de la fase de floración los valores comenzaron a descender llegando a ser negativos. Barrera et al. (2010) destacan que las plantas de girasol en el desarrollo de hojas, tallos y en la fase de floración, tienen mayor necesidad de agua y fotoasimilados debido al proceso de formación de un órgano, mientras que este requerimiento es menor después de cumplirse este proceso.

\subsubsection{Tasa de crecimiento relativo}

La tasa de crecimiento relativo (TCR) fue mayor en la cultivar VC, presentó el valor máximo $\left(0,24 \mathrm{~g} \mathrm{~g}^{-1}\right.$ día $\left.^{-1}\right)$ a los 56 DDS en comparación con las otras cultivares. Se evidenció que las tres cultivares presentaron dos puntos máximos promedio de TCR (Figura 6), el primero a los $27 \mathrm{DDS}\left(0,21 \mathrm{~g} \mathrm{~g}^{-1}\right.$ día $\left.^{-1}\right)$ y el segundo a los 36 DDS $\left(0,11 \mathrm{~g} \mathrm{~g}^{-1}\right.$ día $\left.^{-1}\right)$, en el primer punto se encuentra la fase de desarrollo de nuevas hojas, mientras que en el segundo se destaca la aparición del órgano floral. La TCR es el logaritmo natural de la masa seca estimada a través del tiempo (Barrera et al., 2010), estos autores afirman que la mayor TCR se debe al proceso de división celular y la translocación de fotoasimilados cuando aparecen las nuevas hojas en el tallo y en la fase de floración. La TCR es una medida matemática que permite estimar la capacidad de la planta para generar un nuevo tejido meristemático, esta variable se centra específicamente en la translocación de fotoasimilados hacia el órgano que está empezando su desarrollo en la planta, a diferencia de la TCA que contempla toda la parte aérea de la planta (Arriagada González, 2016).

\subsubsection{Tasa de crecimiento del cultivo}

La tasa de crecimiento del cultivo (TCC) fue mayor en la cultivar VC, presentó su valor máximo $\left(49,52 \mathrm{~g} \mathrm{~m}^{2}\right.$ día $\left.^{-1}\right)$ a los 56 DDS en comparación con las otras cultivares. Se evidenció que las tres cultivares presentaron mayor TCC (acumulación de $\mathrm{g} \mathrm{m}^{2}$ día $^{-1}$ ) (Figura 7), en la fase de crecimiento longitudinal del tallo hasta el fin de la floración, al terminar la fase de floración los valores comenzaron a descender llegando a ser negativos. La TCC es un parámetro de productividad agrícola utilizada en varios cultivos (Mora-Aguilar et al., 2006), esta variable determina la ganancia de masa seca de una planta o una población en un área determinada a través del tiempo (Jerez Mompie et al., 2016). Los máximos valores se deben a que existe ganancia de peso de tres órganos al mismo tiempo (hojas, tallos e inflorescencia), los valores negativos se presentan al terminar la floración debido a que las hojas y tallos paran sus procesos metabólicos, para que las flores empiecen a acumular nutrientes y formar las semillas. Un estudio realizado por Jerez Mompie et al. (2016) en cultivos de ciclo corto explica que generalmente la TCC aumenta con la emergencia de la plántula, y los valores máximos dependen de la eficiencia fotosintética del área foliar y duración de ésta. En ciertos casos la TCC puede ser negativa debido a una alta senescencia de hojas bajeras de la planta en comparación con el crecimiento, de esta forma existe menor acumulación y distribución de biomasa, acompañado de menor área foliar (Arriagada González, 2016). 


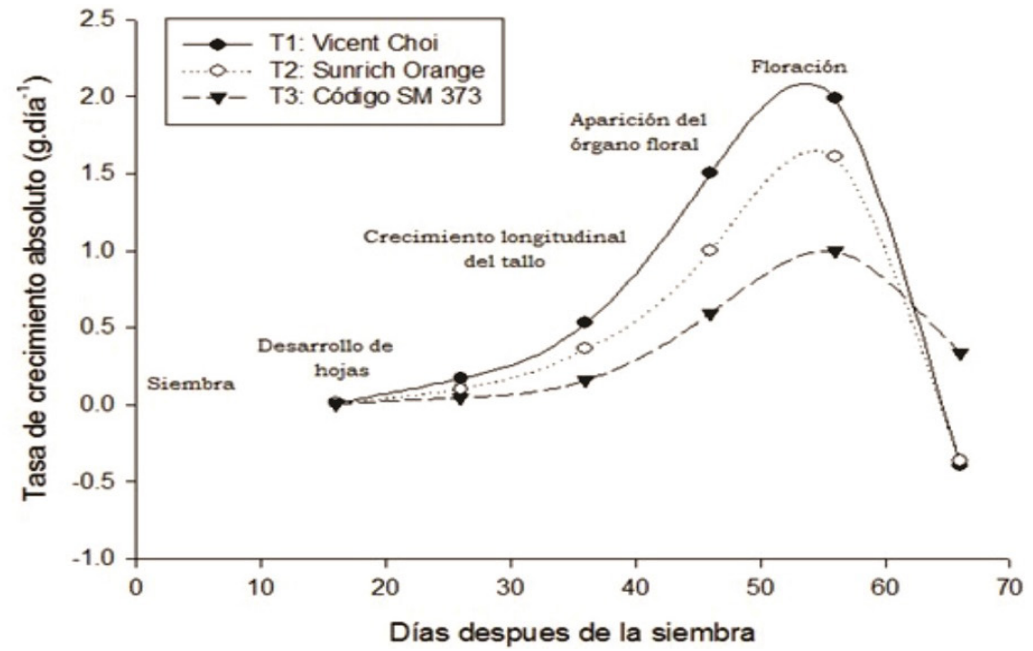

Figura 5. Tasa de crecimiento absoluto de tres cultivares híbridos de girasol en función del tiempo. Figure 5. Absolute growth rate of three sunflower hybrid cultivars in relation to time.

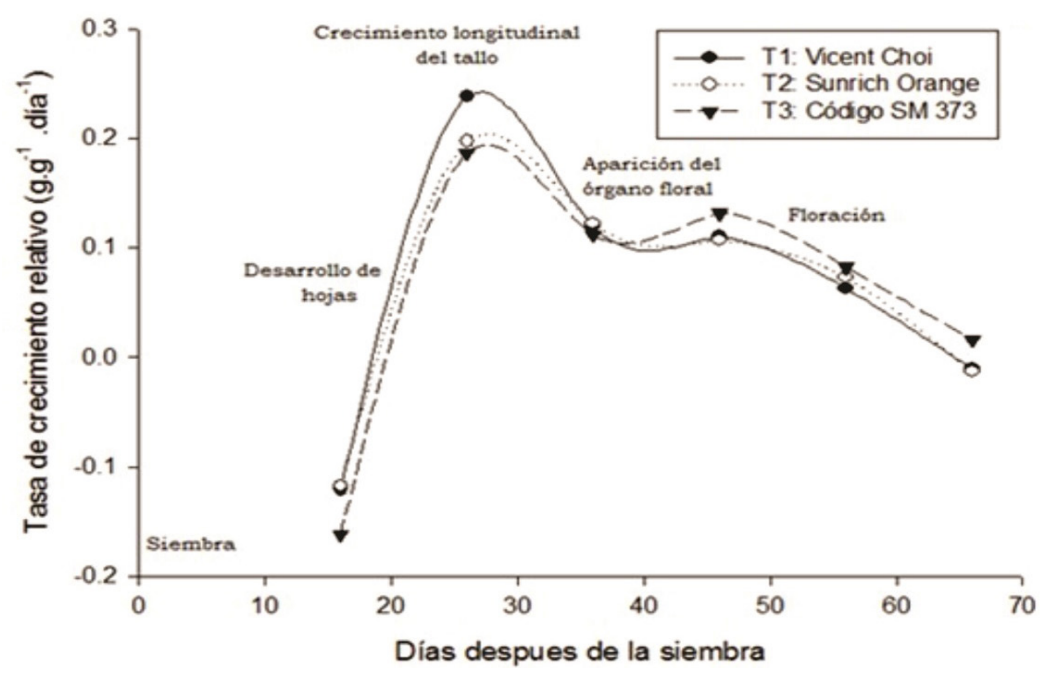

Figura 6. Tasa de crecimiento relativo en tres cultivares de girasol en función del tiempo.

Figure 6. Relative growth rate of three sunflower hybrid cultivars in relation to the cultivation time

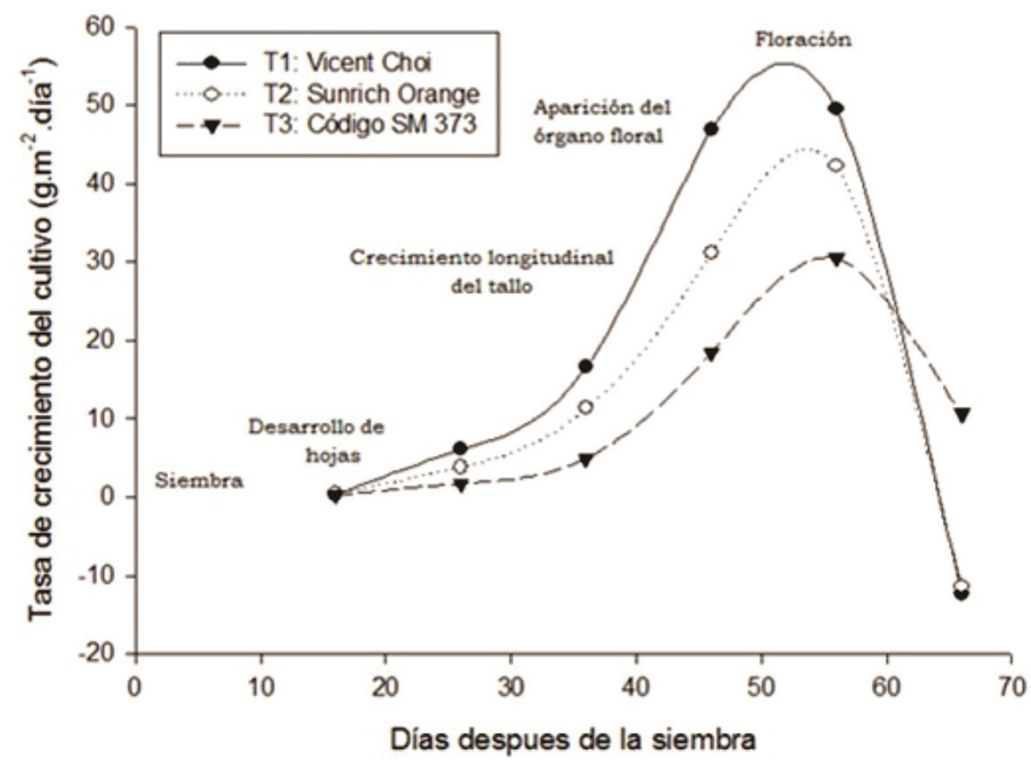

Figura 7. Tasa de crecimiento de tres cultivares híbridos de girasol en función del tiempo.

Figure 7. Growth rate of three sunflower hybrid cultivars in relation to cultivation time. 


\section{7. Índices foliares}

\subsection{1. Área foliar}

La cultivar VC alcanzó el valor de área foliar (AF) más alto $\left(2.052,52 \mathrm{~cm}^{2}\right)$ a los 56 DDS en comparación a las otras cultivares, el valor de AF promedio de las tres cultivares fue $1.418,35 \mathrm{~cm}^{2}$. Di Benedetto y Tognetti (2016) afirman que el AF del girasol tiene influencia directa en los procesos de fotosíntesis (formación de fotoasimilados) y respiración. En la presente investigación el AF tuvo mayor crecimiento desde el desarrollo de las hojas hasta la mitad de la fase de floración, luego de esta fase el crecimiento del AF disminuye considerablemente (Figura 8), similares tendencias obtuvieron Corral et al. (2014) al estudiar el comportamiento del área foliar en girasol. Según Olalde Gutiérrez et al. (2000) afirman que otro factor que contribuye a la disminución del AF al final del ciclo de los cultivos es el proceso de senescencia de las hojas bajeras.

\subsection{2. Índice de área foliar}

El índice de área foliar (IAF) fue mayor en la cultivar VC $(2,37)$ a los 46 DDS en comparación a las otras cultivares (Figura 9), el IAF indica que la cultivar VC tiene mayor capacidad fotosintética en comparación a las otras cultivares. Borrego et al. (2000) mencionan que el IAF permite determinar la capacidad de fotosíntesis de una planta en un área determinada del suelo, además la producción de masa seca está directamente relacionada con el IAF, por esta razón cuando el IAF es alto se espera una mayor acumulación de masa seca (Jerez Mompie et al., 2016), es así que existe relación estrecha entre los días de mayor IAF con el periodo de floración, en el que se presenta mayor acumulación de masa seca de los tratamientos en estudio.

\subsubsection{Relación área foliar}

La cultivar VC alcanzó el mejor valor de relación área foliar (RAF) $\left(134,84 \mathrm{~cm}^{2} \mathrm{~g}^{-1}\right)$ a los 46 DDS (Figura 10) en comparación a las otras cultivares, en los tres tratamientos se presentaron valores altos de RAF en las fases iniciales de crecimiento, tomando en cuenta que la cultivar VC tuvo mayor número de hojas al momento de la primera colecta de datos. Borrego et al. (2000) afirman que un valor alto de RAF en los estados iniciales de desarrollo de las plantas se relaciona con la mayor utilización de fotoasimilados de las plantas para su crecimiento y desarrollo, principalmente de las hojas fotosintéticamente activas.

En esta investigación las tres cultivares después de alcanzar su máximo valor de RAF promedio $(122,58$ $\mathrm{cm}^{2} \mathrm{~g}^{-1}$ ) presentaron descensos del contenido de materia vegetal aérea, debido al proceso de defoliación y aumento de biomasa del tallo. Trápani (2004) resaltan que los valores de RAF tienden a bajar después del desarrollo inicial de los órganos fotosintéticamente activos, es decir, hay un proceso de translocación de fotoasimilados de las hojas, el tallo y la inflorescencia en el siguiente estadio, dando como resultado mayor ganancia de masa seca de estos órganos, en relación con el aumento de área foliar.

\subsection{Producción}

Los promedios de diámetro de inflorescencia y longitud de tallo de los tratamientos en estudio presentan diferencias significativas mediante el ADEVA (Anexo 3). Para las dos evaluaciones fueron identificados tres rangos de significancia, siendo la cultivar VC la que tuvo mayor diámetro de inflorescencia y longitud de tallo en relación con las otras cultivares (Tabla 6).

Tabla 6. Comparación de medias* para diámetro de inflorescencia, longitud y diámetro del tallo de tres cultivares híbridos de girasol. Table 6. Mean comparison for inflorescence diameter, stem length and stem diameter of three sunflower hybrid cultivars.

\begin{tabular}{lcc}
\hline Identificación & Diámetro de inflorescencia & Longitud de tallo \\
\hline VC & $51,44 \mathrm{~A}$ & $115,91 \mathrm{~A}$ \\
SO & $49,61 \mathrm{~B}$ & $83,69 \mathrm{~B}$ \\
$\mathrm{CSM}$ & $35,40 \mathrm{C}$ & $62,48 \mathrm{C}$ \\
\hline CV $(\%)$ & $\mathbf{7 , 7 6}$ & $\mathbf{4 , 9 9}$ \\
\hline
\end{tabular}




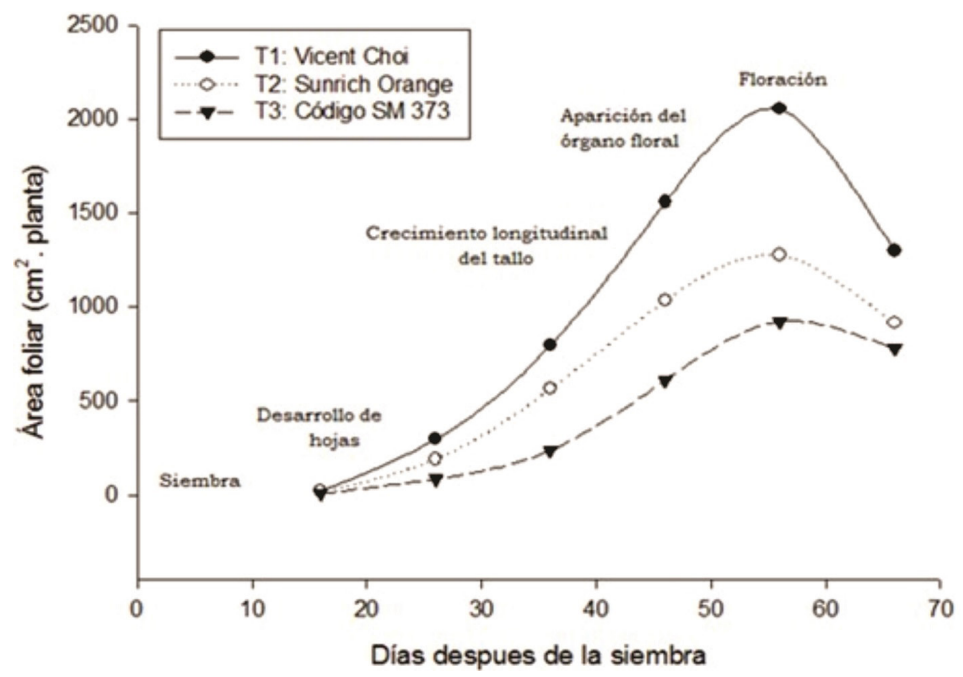

Figura 8. Área Foliar de tres cultivares híbridos de girasol en función del tiempo.

Figure 8. Leaf area of three sunflower cultivars in relation to cultivation time.

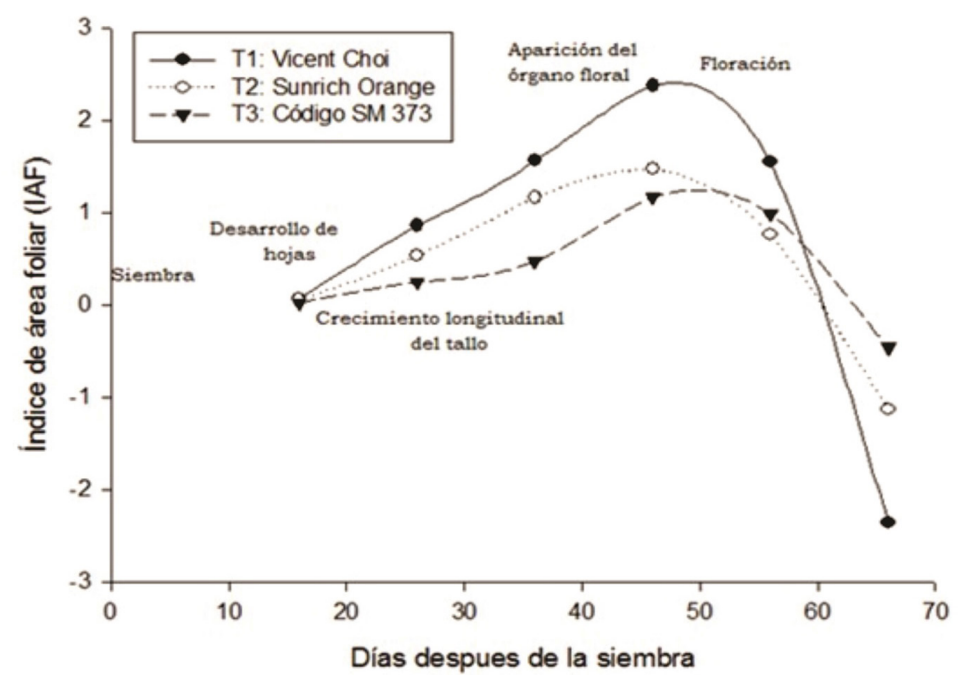

Figura 9. Índice de área foliar de tres cultivares híbridos de girasol en función del tiempo. Figure 9. Leaf area index of three sunflower hybrid cultivars in relation to cultivation time.

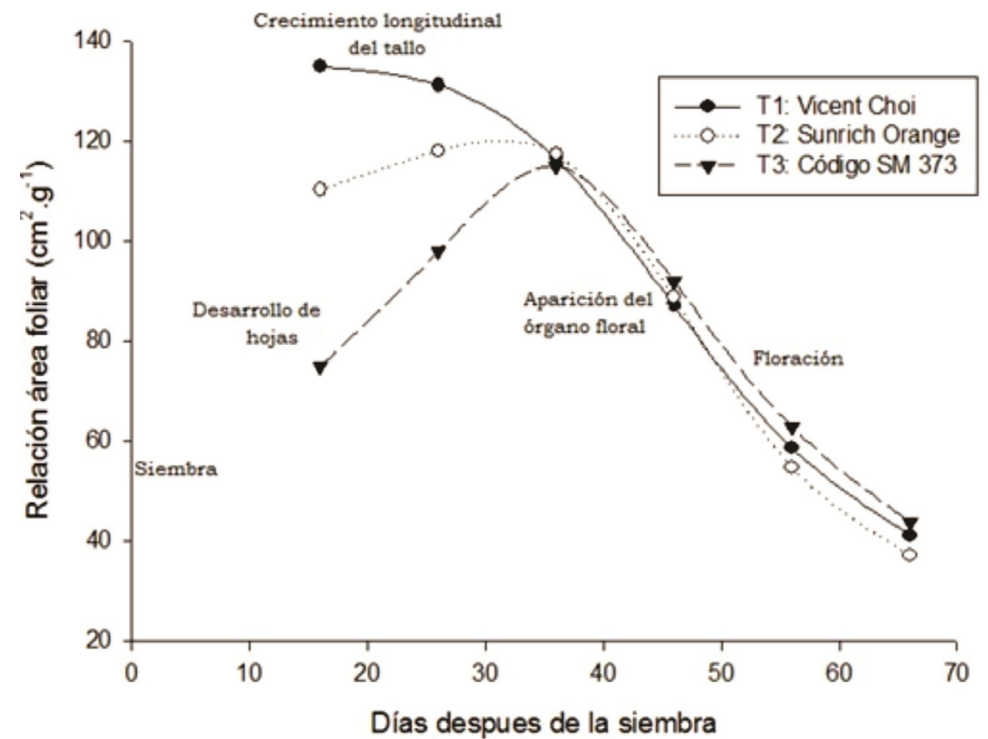

Figura 10. Tasa del área foliar de tres cultivares híbridos de girasol en función del tiempo. Figure 10. Leaf area ratio of three sunflower hybrid cultivars in relation to cultivation time. 
El diámetro promedio de las tres cultivares de inflorescencia y longitud de tallo fue de 45,65 $\mathrm{mm}$ y $87,36 \mathrm{~cm}$, respectivamente (Tabla 6), la cultivar VC presentó valores superiores a la media general en las dos evaluaciones, siendo VC la cultivar con las mejores características de calidad de exportación, al contrario de la cultivar CSM.

La producción en porcentaje de tallos por categoría (Figura 11), reportó $53,33 \%$ tallos médium $(\$ 0,16$ ), $26,24 \%$ tallos select $(\$ 0,22)$ y $20,44 \%$ tallos petite $(\$ 0,10)$ del total cosechado en las tres cultivares de girasol, siendo VC la cultivar con mayor producción de tallos select (231 tallos exportables, $53,72 \%$ de la clase) en comparación a las otras cultivares, resultados respaldados por los valores obtenidos en la clasificación de medias de longitud de tallo y diámetro de inflorescencia Sakata (2021) afirman que la cultivar VC proviene de una línea genética Vicent's reconocida en el mercado por su característica para la floristería; diámetro de capítulo promedio entre $30 \mathrm{~mm}$ y $40 \mathrm{~mm}$.

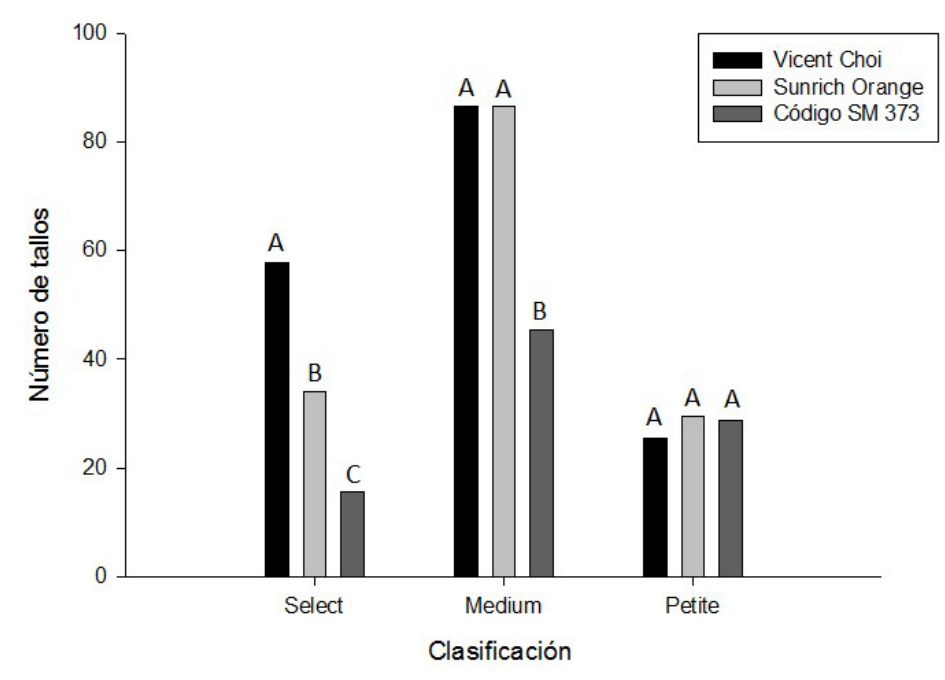

Figura 11. Producción de tallos según categorías de clasificación de tres cultivares híbridos de girasol.

Figure 11. Stem production according to grading categories of three sunflower hybrid cultivars.

\section{Conclusiones}

Las tres cultivares de girasol en estudio presentaron altos porcentajes de germinación, siendo mayores al $90 \%$ y menor rango de días para la cosecha, bajo los 70 días, clasificando a los cultivares híbridos Vicent choice y Sunrich orange como cultivares precoces y al cultivar hibrido Código SM 373 como cultivar precoz-tardía.

La cultivar comercial de girasol Vicent choice presentó las mejores características de crecimiento y morfología con mayor producción y con diámetro de inflorescencia promedio de 51,44 $\mathrm{mm}$.

La acumulación de masa seca total y la de los órganos de las tres cultivares de girasol presentaron tres fases de crecimiento: lento, acelerado y decreciente, obteniendo la mayor acumulación de masa seca en la etapa de floración, y el cultivar híbrido Vicent choice como la cultivar con mayor masa seca en comparación con las otras dos cultivares. El 50,12\% de la biomasa total producida por la planta de girasol es dirigida principalmente al tallo en los tres híbridos estudiados.

Los índices de crecimiento (TCA, TCR y TCC) demostraron que el hibrido comercial Vicent choice fue el cultivar con la mejor eficiencia en acumulación de biomasa y sistema asimilatorio de agua y fotoasimilados de la planta en el ciclo del cultivo de girasol.

Entre los híbridos se marcan diferencias con respecto a los índices de crecimiento evaluados, pero el ciclo de cultivo fue similar entre ellos, por lo que la producción elevada dependerá de la eficiencia fisiológica de cada uno.

El inicio de la floración fue el estadio fenológico con mayor capacidad fotosintética de los tres híbridos en estudio, presentando los valores más altos de área foliar e índice de área foliar, pasados los 45 DDS.

\section{Agradecimientos}

Agradecemos en particular a la Florícola KLD Flowers por permitirnos realizar el trabajo de investigación en sus parcelas de producción; y, al laboratorio de Suelos de la Facultad de Ciencias Agrícolas de la Universidad Central del Ecuador, por el uso de sus instrumentos y materiales para la realización de la investigación. 


\section{Contribuciones de los autores}

- Jairo Fernando Carrillo Criollo: conceptualización, curación de datos, investigación, análisis formal, metodología, administración del proyecto, recursos, validación, visualización, redacción - borrador original.

- María Yumbla Orbes: conceptualización, metodología, administración del proyecto, supervisión, validación, visualización, redacción - borrador original, redacción - revisión y edición.

\section{Referencias}

Arriagada González, C. D. (2016). Efecto de la fecha de siembra en el rendimiento en grano en chia (Salvia hispanica L.) y su relación con el crecimiento y desarrollo. Universidad de Chile. https://repositorio.uchile. $\mathrm{cl} /$ handle/2250/152812

Asociación de Productores y Exportadores de Flores [Expoflores]. (2020). Reporte estadístico anual 2020. Expoflores. https://expoflores.com/wp-content/uploads/2021/03/Anual-Expoflores.pdf

Barrera, J., Suárez, D., y Melgarejo, L. M. (2010). Análisis de crecimiento en plantas. En L. M. Melgarejo (ed.) Experimentos en Fisiología Vegetal (pp. 25-38). Universidad Nacional de Colombia. https://repositorio. unal.edu.co/handle/unal/11144?locale-attribute $=$ en

Biologische Bundesanstait Bundessortenamt and Chemical Industry [BBCH]. (1998). Compendio para la identificación de los estadios fenológicos de especies mono y dicotiledóneas cultivadas, escala BBCH extendida. BBA, BSA, IGZ, IVA, AgrEvo, BASF, Bayer, y Novartis. https://www.agro.basf.es/Documents/es_files/ pdf_1_files/services_files/descarga.pdf

Borrego, F., Fernández, J. M., López, A., Parga, V. M., Murillo, M., y Carvajal, A. (2000). Análisis de crecimiento en siete variedades de papa (Solanum tuberosum L.). Agronomía Mesoamericana, 11(1), 145-149. http://dx.doi.org/10.15517/am.v11i1.17364

Corral, A. C., Irigoyen, A. I., Díaz, V. N., Echarte, L., y Cambareri, M. A. (2014). Crecimiento y dinámica del área foliar verde por planta en maiz bajo tres densidades sin limitaciones de agua y nutrientes. Reunión Binacional Uruguay-Argentina de Agrometeorología y XV Reunión Argentina de Agrometeorología. Piriápolis, Uruguay.

Di Benedetto, A., y Tognetti, J. (2016). Técnicas de análisis de crecimiento de plantas: su aplicación a cultivos intensivos. RIA. Revista de Investigaciones Agropecuarias, 42(3), 258-282. http://ria.inta.gob.ar/contenido/tecnicas-de-analisis-de-crecimiento-de-plantas-su-aplicacion-cultivos-intensivos

Di Rienzo, J. A., Balzarini, M. G., González, L., Casanoves, F., Tablada, M. y Robledo, C. W. (2012). InfoStat versión 1.0. Universidad Nacional de Córdoba (FCA-UNC).

dos-Santos, J. B., Marenco-Centeno, C. R., Vieira de-Azevedo, C. A., Raj-Gheyi, H., de-Lima, G. S., y de-Lira, V. M. (2017). Crecimiento del girasol (Helianthus annuus L.) en función de la salinidad del agua de riego con fertilización nitrogenada. Agrociencia, 51(6), 649-660. https://agrociencia-colpos.mx/index. php/agrociencia/article/view/1317

Escalante Estrada, J. A. (1999). Área foliar, senescencia y rendimiento del girasol de humedad residual en funcion del nitrógeno. Terra Latinoamericana, 17(2), 149-157. https://www.redalyc.org/ articulo.oa? id $=57317208$

Escalante Estrada, Y. I., Escalante Estrada, J. A., Escalante Estrada, L. E., y Escalante, A. (2015). Producción del girasol (Helianthus annuus L.) a diferentes densidades de población cultivado en Chilpancingo, Guerrero, México. Revista de Sistemas Experimentales, 2(5), 174-177. https://www. ecorfan.org/bolivia/researchjournals/Sistemas_Experimentales/vol2num5/Revista_de_Sistemas_ Experimentales_V2_N5-28-31.pdf

Gabriel, J., Angulo, A., Altamirano, O., Rojas, S., y Villegas, J. (2016). Análisis de la distinción, homogeneidad y estabilidad (DHE) de nuevos cultivares de papa (Solanum tuberosum L.) en Bolivia. Revista Latinoamericana de la Papa, 20(1), 56-65. https://doi.org/10.37066/ralap.v20i1.244

Gómez-Arnau, J. (2004). El cultivo del girasol. Hojas Divulgadoras núm. 20/88 HD. Ministerio de Agricultura, Pesca y Alimentación. https://www.miteco.gob.es/ministerio/pags/biblioteca/hojas/hd_1988_20.pdf

Jerez Mompie, E. I., Martín Martín, R., Morales Guevara, D., y Díaz Hernández, Y. (2016). Ánálisis clásico del crecimiento en tres variedades de papa (Solanum tuberosum L.). Cultivos Tropicales, 37(2), 79-87. http:// scielo.sld.cu/scielo.php?script=sci_arttext\&pid=S0258-59362016000200009\&lng=es\&tlng=es 
Lancashire, P. D., Bleiholder, H., Van den Boom, T., Langelüddecke, P., Stauss, R., Weber, E., y Witzenberger, A. (1991). An uniform decimalcode for growth stages of crops and weeds. Annals of Applied Biology, 119(3), 561-601. https://doi.org/10.1111/j.1744-7348.1991.tb04895.x

Montoya, M., Rodríguez, N., Pérez-Almeida, I., Cova, J., y Alemán, 1. (2007). Caracterizacion morfológica de 13 variedades de arroz venezolanas. Agronomía Tropical, 57(4), 299-311. http://ve.scielo.org/scielo. php?script $=$ sci_arttext\&pid=S0002-192X2007000400006

Mora-Aguilar, R., Ortíz-Cereceres, J., Rivera-Peña, A., Mendoza-Castillo, M. C., Colinas-León, M. T., y Lozoya-Saldaña, H. (2006). Índices de eficiencia de genotipos de papa establecidos en condiciones de secano. Revista Chapingo Serie Horticultura, 12(1), 85-94. http://doi. org/10.5154/r.rchsh.2004.09.049

Olalde Gutiérrez, V. M., Escalante Estrada, J. A., Sánchez García, P, Tijerina Chávez, L., Mastache Lagunas, Á. A., y Carreño Román, E. (2000). Crecimiento y distribución de biomasa en girasol en funcióndel nitrógeno y densidad de población en clima cálido. Terra Latinoamericana, 18(4),313-323. https://www. redalyc.org/articulo.oa?id $=57318405$

Ortiz, N., Barbón, R., Capote, A., Pérez, A., y Robaina, M. (2017). Caracterización morfológica en vivero de plantas de Coffea arabica L. cv. Caturra rojo J-884 obtenidas por embriogénesis somática. Biotecnología Vegetal, 17(4), 251-257. https://revista.ibp.co.cu/index.php/BV/ article/view/568

Penichet Cortiza, M., Guerra Garcés, M., y Carballo García, P., y Cortiza, M. (2008). El girasol. Sus posibilidades económico-productivas en el desarrollo agropecuario. Observatorio de la Economía Latinoamericana, 95. https://www.eumed.net/cursecon/ecolat/cu/2008/cgg.htm

Pereira Crespo, S., Fernández Lorenzo, B., Valladares Alonso, J., Díaz Díaz, N., Resch Zafra, C., González Arráez, A., y Flores Calvete, G. (2014). Evolución del rendimiento y calidad del girasol (Helianthus annuus L.) aprovechado para forraje tras la floración y desarrollo de calibraciones NIRS para la predicción del valor nutricional de los componentes morfológicos. Revista Pastos, 44(2), 19-30. http://polired.upm. es/index.php/pastos/article/view/3109

Rincón Guerrero, N., Olarte Quintero, M. A., y Pérez Naranjo, J. C. (2012). Determinación del Área Foliar en Fotografías Tomadas con una Cámara Web, un Teléfono Celular o una Cámara Semiprofesional. Revista Facultad Nacional de Agronomía Medellín, 65(1), 6399-6405. https://revistas.unal.edu.co/index.php/refame/article/view/30766

Sakata. (2021). Flower Catalogue Seeds 2021-2022. https://sakataornamentals.eu/catalogues/sakata-catalogus-2021-seeds/

Tenesaca, M. (2015). Fenología y profundidad radical del cultivo de girasol (Helianthus annuus) var. Sunbright, en el sector Querochaca, cantón Cevallos, provincia de Tungurahua. Universidad Técnica de Ambato. https://repositorio.uta.edu.ec/handle/123456789/10401

Trápani, N. (2004). Fases de desarrollo del cultivo de girasol y los factores determinantes del rendimiento. Boletín Técnico Pioneer. Pioneer. https://www.pioneer.com/CMRoot/International/Argentina/productos_y_servicios/Girasol_boletin.pdf

Weber, E. y Bleiholder, H. P. (1990) Erläuterungen zu den BBCH-Dezimal-Codes für die Entwicklungsstadien von Mais, Raps, Faba-Bohne, Sonnenblume und Erbse -mit Abbildungen.Gesunde Pflanzen, 42, 308-321. 


\section{Anexos}

Anexo 1. ADEVA del porcentaje de emergencia, días a la emergencia y días a la cosecha de tres cultivares de girasol.

\begin{tabular}{lllll}
\hline F.V. & gl & \% de germinación & Días a la emergencia & Días a la cosecha \\
\hline Total & 11 & & & \\
Tratamiento & 2 & $39,13^{* *}$ & $16,20 *$ & $311,33^{* *}$ \\
Bloque & 3 & $0,66^{\mathrm{NS}}$ & $2,20^{\mathrm{NS}}$ & $2,87^{\mathrm{NS}}$ \\
Error & 6 & 0,72 & 1,25 & 0,07 \\
\hline CV \% & $\mathbf{0 , 8 8}$ & $\mathbf{8 , 7 7}$ & $\mathbf{0 , 0 4}$ \\
\hline
\end{tabular}

** Diferencias significativas ( $\mathrm{p}$-valor $<0,01$ ).

$*$ Diferencias significativas ( $\mathrm{p}$-valor $<0,05$ ).

Ns Diferencias no significativas ( $\mathrm{p}$-valor $>0,05$ ).

Anexo 2. ADEVA de la masa fresca y seca de la parte aérea de la planta de tres cultivares de girasol en el punto de corte.

\begin{tabular}{llll}
\hline F.V. & gl & Masa fresca & Masa seca \\
\hline Total & 11 & & $39,73 * *$ \\
Tratamiento & 2 & $6,89^{*}$ & 1,99 Ns \\
Bloque & 3 & $0,90 \mathrm{Ns}$ & 8,57 \\
Error & 6 & 863,48 & $\mathbf{1 1 , 7 1}$ \\
\hline CV \% & & $\mathbf{1 5 , 2 8}$ & \\
\hline
\end{tabular}

*** Diferencias significativas (p-valor $<0,01)$.

* Diferencias significativas ( $\mathrm{p}$-valor $<0,05)$.

${ }^{N S}$ Diferencias no significativas ( $\mathrm{p}$-valor $>0,05$ ).

Anexo 3. ADEVA de diámetro de inflorescencia, longitud y diámetro de tallo de tres cultivares de girasol en el punto de corte.

\begin{tabular}{llll}
\hline F.V. & gl & Diámetro de inflorescencia & Longitud de tallo \\
\hline Total & 11 & & \\
Tratamiento & 2 & $39,13^{* *}$ & $16,20 *$ \\
Bloque & 3 & $0,66^{\mathrm{NS}}$ & $2,20^{\mathrm{NS}}$ \\
Error & 6 & 0,72 & 1,25 \\
\hline CV \% & & $\mathbf{0 , 8 8}$ & $\mathbf{8 , 7 7}$ \\
\hline
\end{tabular}

** Diferencias significativas ( $\mathrm{p}$-valor $<0,01)$.

$*$ Diferencias significativas ( $\mathrm{p}$-valor $<0,05$ ).

Ns Diferencias no significativas ( $\mathrm{p}$-valor $>0,05$ ). 